\title{
DATRADIÇÃO AO PONTO DE CULTURA VOA VOA MARIA: SAMBA DE RODA E ECONOMIA SOLIDÁRIA DA CULTURA
}

\author{
Fernanda Castro de Queiroz
}

\begin{abstract}
Resumo: Desde a sua patrimonialização o samba de roda tem tomado novas configurações. Discutir a reinvenção dessa prática a partir do diálogo entre as políticas de patrimônio, produção cultural e economia solidária da cultura com a gravação do CD e DVD do samba de roda Voa Voa Maria da comunidade de Matarandiba, é o objetivo deste artigo. Para isso, apresenta a cultura enquanto campo de transformação ao invocar que povos e comunidades reelaboram arranjos culturais sem esquecer suas origens culturais.
\end{abstract}

Palavras-chave: Samba de roda. Patrimônio. Economia solidária da cultura.

\section{FROM TRADITIONTO THE PROJECT VOA VOA MARIA: SAMBA DE RODA AND SOLIDARITY ECONOMY OF CULTURE}

\begin{abstract}
Since its patrimonialisation "samba de roda" has taken new configurations. Discussing the reinvention of this practice from the dialogue between heritage policies, cultural production and solidarity economy of the culture with the recording of the cd and DVD of the Voa Voa Maria samba de roda of the community of Matarandiba, is the purpose of this article. To this end, it presents culture as a field of transformation by invoking that peoples and communities rework cultural arrangements without forgetting their cultural origins.
\end{abstract}

Keywords: Samba de roda. Patrimony. Solidarity economy of culture

\section{Introdução}

O samba de roda se tornou Patrimônio Imaterial da Humanidade desde $2004^{1}$, e a partir da sua patrimonialização tem tido um maior destaque

\footnotetext{
${ }^{1}$ A UNESCO (Organização das Nações Unidas para a Educação, a Ciência e Cultura) através da convenção para a salvaguarda do patrimônio cultural imaterial realizada em 2003 considera o patrimônio imaterial como fonte de diversidade cultural e garantia de desenvolvimento sustentável. Reconhece que comunidades e grupos desempenham um papel importante para a manutenção, salvaguarda e recriação do patrimônio imaterial. (UNESCO, 2003). E, por meio dessa convenção, foi proclamada o título de obraprima ao samba de roda.
} 
no cenário baiano e nacional, tanto por parte das políticas voltadas para o samba de roda, quanto por quem faz samba de roda, o que tem levado para além da maior visibilidade, tensões, disputas e reinvenção da tradição samba de roda. Novos grupos surgiram, outros voltaram e outros passaram a se reorganizar. É neste cenário que o samba de roda Voa Voa Maria, da comunidade de Matarandiba, passa a se organizar em torno das práticas comunitárias e das políticas públicas.

A pequena vila de Matarandiba, localizada na contra-costa da ilha de Itaparica, tem reelaborado suas maneiras de viver a partir das suas práticas culturais. O samba de roda, marcante na vida cotidiana da vila tem sido o principal motor dessa transformação, inovando um fazer ancestral - o sambar - tanto para dentro quanto para fora da comunidade em um processo que tem como caminho essencial a memória e a continuidade desse fazer, aliando o diálogo em torno da tradição com novas práticas que possam trazer um maior envolvimento da comunidade com a tradição, ao mesmo tempo que dialoga com elementos de novas dinâmicas nas práticas culturais e da economia solidária.

Com isso, o samba de roda, enquanto tradição, vivência e presença contemporânea, daquele lugar, traz novas perspectivas de atuação para a comunidade e seu povo, justamente por conseguir fazer da tradição um processo constante de renovação, não estático, mas sim em um movimento cotidiano em torno do e mediante o samba de roda. As reflexões apresentadas neste artigo fazem parte da pesquisa etnográfica de Mestrado no Programa de Pós Graduação em Antropologia da Universidade Federal da Bahia (UFBA). Esse artigo pretende demonstrar como tem sido esse processo reinventivo a partir da inserção do samba de roda nas políticas de patrimônio, bem como de economia solidária da cultura, realizado pelo grupo samba de roda Voa Voa Maria. 


\section{Samba ê sambá, samba de matarandiba: é samba de vera cruz, é cultura brasileira ${ }^{2}$}

É dentro de um cenário exuberante de Mata Atlântica, rodeada pelas águas da Baía de Todos os Santos que está localizada a pequena comunidade de Matarandiba. A comunidade se situa na contra-costa da Baía de Todos os Santos distante da sede do município - Mar Grande - $33 \mathrm{~km}$.

Até os anos 60 a comunidade mantinha uma maior relação com a região do Recôncavo Baiano, pois as mais diversas transações econômicas e culturais aconteciam sobretudo com essa região, pela facilidade que o transporte marítimo criava na Baía de Todos os Santos. Essa realidade vai se alterando gradativamente com a construção de uma malha rodoviária para a ligação com o continente feita pela a empresa Dow Brasil, que compra 90\% do território e instala uma planta de extração de sal mineral. Essa intervenção transforma significamente a vila, tanto no que tange a sua relação com o território local como quanto com a parte maior da ilha de Itaparica, já que passa agora ter mais facilidade para chegar ao continente a partir de uma maior mobilidade através de carros.

Essa mobilidade, no entanto, foi sendo realizada ao longo do tempo de maneira lenta e vigiada. Apesar da crescente mobilidade ao longo dos anos, o modo de viver se mantém em um ritmo muito próprio, regido pelo tempo das marés e com suas tradições e festejos realizados dentro das dinâmicas das marisqueiras e pescadores que as realizam.

A comunidade de marisqueiras e pescadores tem cerca de mil famílias e tem como principal atividade econômica a pesca e a mariscagem. E, apesar de ser uma comunidade ainda carente de serviços essenciais e básicos para a população, a vila tem construído novas maneiras de organização social e comunitária que tem alterado as dinâmicas econômicas, sociais e culturais através da Rede Matarandiba de Economia Solidária e Cultura. A rede surge da insatisfação da comunidade com os trabalhos de mitigação que eram desenvolvidos pela empresa.

Constituída desde 2007 através de uma parceria da Comunidade, Ites $^{3}$ e Dow, que decidiram por desenvolver um projeto com base na economia

2 Trecho da música Samba de Matarandiba do samba de roda Voa Voa Maria.

${ }^{3}$ Incubadora Tecnológica de Economia Solidária e Gestão do Desenvolvimento Territorial. 
solidária e que não fosse passageiro, mas que pudesse, além de dialogar com toda a comunidade, ser mais perdurável. Dessa parceria foi concebida a Rede Matarandiba de Economia Solidária e Cultura. A constituição da rede teve como princípio norteador a economia solidária que se organiza sobre o prisma da solidariedade e da democracia para enfrentar problemáticas locais. (FRANÇA FILHO; LA VILLE, 2004).

Ou seja, estabelecer novas maneiras de produção na comunidade que abarcasse uma nova noção de desenvolvimento local a partir da construção de uma rede que "implica a valorização do potencial de constituição de novos circuitos de trocas e relações econômicas integradas ao conjunto das esferas de estruturação da vida no lugar" (RELATÓRIO ECOSMAR, FASE 1, 2008). Para isso, foi utilizado o processo de incubação através da Ites/UFBA. As incubadoras são “iniciativas acadêmicas que integram ensino, pesquisa e extensão e que tem como prática a promoção da interação entre o meio universitário com grupos de trabalhadores" (RELATÓRIO PRONINC, 2017, p. 31).

No transcurso de formação foi criada a Associação Comunitária de Matarandiba (Ascoma), que exerce um papel de interlocução com a Dow e com a comunidade em relação aos mais diversos problemas na comunidade e em relação os empreendimentos ligados a Rede Matarandiba de Economia Solidária e Cultura. Hoje a comunidade tem onze empreendimentos econômicos solidários como rádio comunitária, ostreicultura, horta agroecológica, padaria comunitária, Vivertur (vivência turística de base comunitária) e etc.

Logo após a criação da Ascoma se dá a articulação para a criação da Associação Sócio Cultural de Matarandiba (ASCOMAT), o processo de mobilização o qual passava a comunidade refletiu em um grupo de mulheres que resolveu criar a associação e fazer um trabalho em torno das práticas culturais existentes na comunidade que estavam frágeis ou momentaneamente esquecidas.

A Ascomat é composta em sua maioria por mulheres e iniciou suas articulações em um processo de diálogo com os mais antigos para reviver o 
Terno da Flores e o auto do Zé de Vale 4 , que não se apresentavam há 50 anos, além de fortalecer as práticas que ainda estavam ocorrendo na comunidade como o Boi Estrela e o samba de roda. Hoje, a Ascomat é responsável pela produção das práticas culturais da comunidade com as diversas manifestações populares locais como:

- $\quad$ Samba de roda

- $\quad$ Auto do Zé de Vale

- Boi Estrela

- $\quad$ Presente para Iemanjá

- Festa de São Gonçalo

- $\quad$ Aruê $^{5}$

- Terno das Flores

- $\quad$ Lavagem da Fonte ${ }^{6}$

Sendo que na maioria estas ações e tradições estão sendo preservadas e promovidas pela articulação dos pontos e projetos de cultura, além da constante mobilização com as crianças com a criação do samba de roda, boi e terno mirins na comunidade que tem um alto nível de organização.

- $\quad$ Ponto de Memória Tia Dina

- $\quad$ Ponto de Leitura Tia Dazinha

- $\quad$ Ponto de Cultura Voa Voa Maria

- $\quad$ Projeto De Vento em Popa

\footnotetext{
${ }^{4}$ Auto popular encenado na Vila de Matarandiba que ficou mais de 50 anos sem acontecer e desde 2007 tem sido realizado todo ano. $\mathrm{O}$ auto gira em torno do personagem que leva o nome de Zé de Vale, filho de uma senhora rica da localidade e que devido ao seu comportamento "arruaceiro", é preso no canavial. Não contente com a situação do filho, sua mãe vai à procura das mais distintas autoridades, do coronel ao presidente, tentando persuadi-las a soltá-lo. Em troca da liberdade de Zé de Vale sua mãe oferece dinheiro, cavalo, uma barquinha, mas este só é solto quando o pedido é feito em nome da bandeira do divino Espírito Santo.

${ }^{5} \mathrm{O}$ ano velho é representado por uma padiola de bananeira, ornamentada a rigor com folhas e flores da mata local. O cortejo sai do Alto do Cruzeiro percorrendo todas as ruas e becos da vila. Precisamente à meia noite, homens carregando o ano velho adentram ao mar e o atiram às águas e a entrada do ano é festejada com samba.

${ }^{6}$ Após os festejos de São João as mulheres iam para a fonte lavar as roupas e utensílios usados. Ao final dos trabalhos elas se reuniam e dividiam entre si as sobras das iguarias feitas para o São João e aproveitavam para fazer um grande samba. Essa tradição se mantém até hoje.
} 
Todo o processo de reorganização das manifestações e a implantação dos pontos foram realizados através de uma metodologia que privilegia o diálogo entre as gerações. Espaços como as rodas de memória são criados para que os mais antigos possam contar como aconteciam os festejos em atividades gravadas, filmadas e fotografadas. Com isso, as manifestações puderam voltar a ocorrer e estabelecer ainda mais os laços dos mais jovens com os mais antigos o que reflete no fortalecimento da identidade local.

Essa realidade que hoje vive a comunidade vive atualmente, vem há mais de dez anos sendo construída e refeita. O projeto que inicialmente tinha duração de dois anos conseguiu se manter, reinventar e gerar novas possibilidades para a comunidade. Desde a sua criação conseguiu implementar onze empreendimentos de economia solidária e cultura possibilitando fortalecer a economia local, além dos aspectos sociais e culturais. Atualmente a rede se mantém, além dos repasses da empresa Dow, através de editais públicos, articulação com outras redes e mobilização local como bingos, rifas, etc. Esse cenário possibilitou uma re-organização das manifestações populares em geral, e o samba de roda se insere nessa conjuntura, no sentido de refletir na sua prática as transformações da comunidade, tanto pela Rede Matarandiba de Economia Solidária e Cultura, bem pela patrimonialização.

\section{Que samba é esse que eu nunca ouvi falar? é o samba voa voa Maria $^{7}$}

O samba de roda carrega na sua prática cotidiana memórias e reinvenções que contribuem para a sua perpetuação. Composto que envolve a música, dança e ancestralidade e invoca uma estética africana e diaspórica, ele expressa o lugar do povo negro, suas resistências. “Os pés no chão vão riscando... quadris a balançar"s.

Ele está em diversos territórios da Bahia e também de diversas formas, "o samba de roda ocorre em todo o Estado da Bahia. Apresenta inúmeras variações que parecem estar relacionadas com aspectos ecológicos,

\footnotetext{
${ }^{7}$ Trecho retirado da música Voa Voa Maria do samba de roda Voa Voa Maria.

${ }^{8}$ Trecho da música Tamarineira do samba de roda Voa Voa Maria.
} 
históricos e socioeconômicos das diferentes regiões do Estado" (DOSSIÊ IPHAN, 2006, p. 17). No entanto, o Recôncavo da Bahia carrega um significado central na formação do Estado da Bahia e no que diz respeito ao samba de roda tem sido a grande referência.

O Recôncavo Baiano 9 recebeu grande quantidade de escravos a partir do século XVI de várias regiões da África, possibilitou a constituição dessa região com os traços das heranças culturais desses povos através de danças, cantos e ritmos que desempenham um papel crucial para o contexto cultural da região (GRAEEF, 2015). Destacam-se neste cenário a cidade de Santo Amaro e Cachoeira como grandes pontos do samba de roda, apesar dele existir em todo o recôncavo que abarca região metropolitana de Salvador e Ilha de Itaparica.

Hoje, o samba de roda é Patrimônio Imaterial da Humanidade. Segundo o Dossiê Iphan (2006), o seu principal legado é a salvaguarda através de um conjunto de objetivos para a valorização do samba de roda, dentre eles: revitalizar no Recôncavo a feitura artesanal de violas de samba e em especial de machetes, apoio ao processo de organização do conselho de Sambadores que culminou com a criação da Associação dos Sambadores e Sambadeiras da Bahia (ASSEBA) -, e a criação das redes de Casas do Samba com sua sede em Santo Amaro.

Além de propiciar um conjunto de objetivos que possa desenvolver políticas públicas de fomento e preservação ao samba de roda, a patrimonialização traz também um olhar sobre o fazer de povos e comunidades que historicamente foram subjugados, sendo a primeira expressão cultural de matriz africana do Brasil a ser reconhecido como patrimônio imaterial, como um "importante marco num país com um histórico de políticas e discursos racistas que procura(va)m, omitir, diminuir/ou embranquecer as participações e criações negras na construção sociocultural, estética e negra" (DÖRING, 2016, p. 17).

Com este panorama, o processo de patrimonialização aponta novas perspectivas ao samba de roda e o coloca em um cenário que já não se limita a povos e comunidades, mas chega a públicos e organizações diversas. Para Döring (2013) é dentro de um processo dialético que é necessário avaliar os

${ }^{9}$ A faixa de terra que contorna a Baía de Todos os Santos, formada por mangues, baixas e tabuleiros, é conhecida como a Região do Recôncavo. 
caminhos da salvaguarda, já que "o samba de roda se manifesta através das pessoas, de suas práticas, memórias e histórias individuais, relacionados a contextos específicos [...] que tem sido influenciados e atingidos pelo reconhecimento do samba de roda como patrimônio imaterial" (DÖRING, 2013, p. 148).

Nesse sentido, é importante atentar para as transformações que passam o samba de roda, sem negar ou cristalizar o seu fazer, mas observar as maneiras que esses grupos têm se apropriado desse processo de salvaguarda que está dentro de um contexto amplo pautado pela necessidade de preservação da tradição e ao mesmo tempo está inserido em um mundo globalizado. Para isso, é necessário ver a cultura como algo histórico e não estático e que se refaz.

Sahlins (1997) destaca que a cultura assumiu uma variedade de novas configurações com um "florescimento cultural" que se refaz dentro da lógica ocidental capitalista, subvertendo-a e invocando discursos sobre a liberdade cultural. $\mathrm{O}$ autor aponta que a cultura não está fadada ao desaparecimento, mas justamente, tem revertido uma lógica de exotismo e folclorização que perdurou sobre esses povos e conseguido reinventar suas maneiras de viver dentro da globalização: "os povos a utilizam não apenas para marcar sua identidade, como para retomar o controle do próprio destino" (SAHLINS, 1997, p. 46).

Ao pensar a cultura a partir deste lugar, onde ela tem sido refeita, a noção de cultura popular também se refaz, Abib (2017) salienta a necessidade de ter uma noção atualizada de cultura popular que abandone a visão essencialista que a caracterizava, para abrir novas possibilidades de articulação e interesses culturais e específicos, de grupos que buscam recuperar e reconstruir suas raízes culturais.

Desta maneira, é preciso compreender essas novas dinâmicas e vêlas não como um fazer estático e centrado, mas sim, que está inserido dentro de transformações complexas e desenraizadas cuja presença se expande em diferentes locais do mundo globalizado. E que, para Abib (2017) cria novas relações tanto economicamente quanto politicamente, onde muitos grupos e comunidades têm, na sua atividade cultural, maneiras de obtenção de recursos econômicos e de sobrevivência e maior organização em torno de reivindicações específicas e luta por mais autonomia. 
A partir desses pressupostos é possível compreender o cenário que o samba de roda passa a construir com a sua patrimonialização dando novos contornos à sua prática. Com um fazer que dialoga tanto para dentro quanto para fora da comunidade, em dinâmicas culturais e econômicas, já que "para a vida contemporânea, patrimônio significa, mais do que nunca, riqueza acumulada por gerações passadas, e que é hoje indispensável como recurso" (ARANTES, 2001, p. 130).

Nesse sentido, retomo Döring (2013) quando analisa os impactos sofridos pelo samba de roda com a patrimonialização: Mudanças socioculturais, devidas à valorização do samba de roda e seus protagonistas, mudanças nas relações entre os mestres que passam a ser mais conhecidos, ao mesmo tempo que surgem tensões políticas com a ASSEBA, ademais, tensão entre tradição e contemporaneidade, maior evidência da produção cultural e a relação com o mundo midiático. Após a patrimonialização, o samba de roda toma novos contornos e olhar para esses aspectos é uma maneira de enxergar como esse fazer tem se desdobrado tanto para as suas comunidades quanto para outros cenários que passam a ser inseridos.

É dentro dessa perspectiva que trago o samba de Roda Voa Voa Maria, samba da comunidade de Matarandiba que começa a ser refeito no processo de patrimonialização, mas que por diversos momentos esteve distante das pautas políticas que passavam outros sambas. Nesse sentido, dois pontos são essenciais para a construção desse cenário. Primeiro, por estar localizado em uma comunidade distante geograficamente do centro onde mais fortemente estava sendo pautada a patrimonialização como as cidades de Santo Amaro ou Cachoeira. Depois, pelo frágil diálogo com a ASSEBA que não consegue levar a sua mobilização para a Ilha de Itaparica, bem como a concentração de suas atividades nas cidades de Santo Amaro ou Cachoeira.

Com isso, as atividades realizadas pela entidade ou não chegavam até o grupo de samba Voa Voa Maria ou chegavam muito próxima da data de realização o que dificultava o deslocamento do grupo. Uma vez que, se deslocar sempre pra Santo Amaro quase nunca era possível, tanto financeiramente como por uma falta de diálogo que criasse um sentimento de pertença ao conjunto de ações que eram e são realizadas pela ASSEBA.

Apesar do município de Vera Cruz fazer parte dos territórios abarcados pelo Recôncavo da Bahia, de acordo com o Dossiê Iphan (2006), pouco tem sido a inserção das políticas de salvaguarda na região, sobretudo 
pela incapacidade de articulação da ASSEBA com os grupos locais que hoje são em torno de 13 grupos entre adultos e mirins.

Apesar disso, os reflexos da patrimonialização também chegavam de maneira mais dispersas ao Voa Voa Maria que por conta da sua articulação era um dos grupos que mais conseguiam e consegue dialogar com a ASSEBA. Porém, a comunidade estava mergulhada em uma dinâmica de transformação com a Rede de Economia Solidária e Cultura que também refletia no fazer do samba de roda e a colocava em contato com, por exemplo, editais públicos e outras redes o que facilitou esse processo. Do diálogo dessa organização comunitária que vivia a comunidade, com o processo de patrimonialização do samba de roda, o Voa Voa Maria tem se feito a partir destas linhas. Segundo a Mestra Marica, o samba de roda de Matarandiba era bem diferente do que é hoje:

O samba antigamente era assim, não tinha muitos instrumentos, era um samba feito por nós, era palma da mão, os fundos das panelas, às vezes aparecia um pandeiro, quando vinha alguém de fora trazia uma viola era mais animação, mais canto e palma. ${ }^{10}$

D. Jandira, marisqueira e sambadeira, diz que samba desde criança e que tudo na comunidade terminava em samba, São João, Aruê e que era cantando, batendo palma, e os instrumentos quando tinha "eram o pandeiro e o tambor feitos de couro de jibóia e camaleão".

O samba em Matarandiba era uma prática que perpassava todo fazer da comunidade, festas, rituais, aniversários, mariscar, pescar, lavar roupas nas fontes, o dia-a-dia estava associado a fazer samba “A gente dizia onde vai ser o samba hoje? ah! na casa de fulano e a gente ia"(Mestra Marica), com poucos instrumentos e palmas e vozes. Desde de $2007 \mathrm{com}$ a fundação da Associação Sócio Cultural de Matarandiba (Ascomat) esse fazer vem passando por diversas transformações. Deixou de ser uma prática apenas do fundo do quintal, das festas, das noites de lua, para ser algo mais organizado com ensaios, apresentações, composição de figurinos, etc.

Atualmente o samba Voa Voa Maria tem 58 participantes, com 45 sambadeiras e 13 tocadores entre a idade de 25 a 70 anos. Começou a se

\footnotetext{
${ }^{10}$ Mestra Marica - Entrevista em 14 de abril 2018, Matarandiba.
} 
articular com a retomada das manifestações culturais na comunidade como o Zé de Vale e Terno das Flores.

Durante uma reunião do terno, Gilson, filho da Mestra Marica, sugeriu organizar o samba, já que ele também estava enfraquecido na comunidade e ele gostaria muito de ver o samba forte novamente, a mãe dele canta e é do samba desde pequena e ele queria homenagear ela. Fizemos rifa, compramos pano e mandamos fazer as roupas, cada um trouxe seu instrumento, convidamos o samba de Mutá e fizemos uma linda festa. ${ }^{11}$

Desde então o samba de roda Voa Voa Maria tem aprimorado a sua organização em torno das suas práticas culturais, se apresentado em outros lugares, inclusive fora do Estado da Bahia e se tornado uma referência na Ilha de Itaparica. Em 2012 a TVE Bahia exibe uma matéria falando sobre as manifestações culturais da comunidade de Matarandiba, no ano de 2015, através da ASCOMAT, ganhou o edital de culturas populares da Secretaria de Cultura da Bahia e realizou o I Encontro de Samba de Roda da Ilha de Itaparica: Samba no Mar, que reuniu todos os sambas da região entre adultos e mirins, pesquisadores do samba de roda e o poder público local. Em 2016 ganhou o prêmio do Instituto do Patrimônio Histórico e Artístico Nacional (IPHAN) de salvaguarda de boas práticas da cultura popular, o único do Estado da Bahia. E em 2015 ganha o edital dos Pontos de Cultura para a gravação do primeiro CD, mas que somente começou a ser realizado em 2017.

A organização do samba se dá em torno de um grupo de trabalho que tem a Mestra Marica considerada como responsável por ter uma relação com o samba que vem de uma tradição da sua família e que continua sendo mantida. Mas o samba de roda de Matarandiba tem uma particularidade de, apesar de tê-la como Mestra, as suas decisões serem todas coletivas o que reflete a articulação e formação comunitária que passou e que ainda passa a comunidade. O samba se reúne sempre que é necessário tomar alguma decisão importante como decidir indumentárias, apresentações, viagens, etc.

Esse processo mais horizontal de organização tem se fortalecido ao longo desses anos e propicia um maior engajamento dos participantes no fazer samba de roda, que nesta perspectiva, altera o samba de roda para além do encontro musical, o sambar e tocar, mas também o pauta no que se refere a

${ }^{11}$ Adenildes, coordenadora da Ascomat - entrevista em 29 de maio de 2018, Matarandiba. 
sua produção. Essa alteração traz ao samba de roda uma roupagem que dialoga com processos externos a comunidade. Sua maneira de organização, por exemplo, não se limita mais a espontaneidade do momento, mas também é pensada dentro de uma estrutura de datas, horários, apresentações e convites.

O que tem incluído o samba em espaços e organizações que nem sempre estiveram acostumados a estar e isto transporta o papel mais local que sempre teve, ao mesmo tempo que o insere tanto na perspectiva da patrimonialização quanto da configuração pela qual passa a cultura popular que não é um processo de esvaziamento ou esgotamento, ao contrário, "adquire novos significados a partir de um processo de tradições culturais de grupos que portam marcas sociais e culturais diversas, que os diferenciam no contexto social" (ABIB, 2017; p. 81).

Muito significante nesse papel tem sido a representação das mulheres, maioria no samba, que tem conseguido ocupar espaços que sempre foram pré-determinados como distante delas, como espaços de decisão ou organizativos "quando as mulheres se dão conta de sua relevância econômica e se constituem em agentes políticos, também criam ou reforçam as identidades de sua comunidade" (MANESCHY; SIQUEIRA; ÁLVARES, 2012, p. 772). O que tem ampliado a participação das mulheres nas diversas maneiras que o samba tem de estar presente, seja cantando, tocando, compondo músicas e nos momentos mais "burocráticos".

Ao dizer isso, não desloco o que entendo por uma participação das mulheres no samba que é parte estrutural dessa prática, nem nego que o ato de sambar já é um ato político e de resistência, ao contrário, o fazer samba de roda é um ato político com tudo que a sua estética carrega "o samba de roda, como muitas tradições cênicos-musicais de matriz africana, sempre foi música/dança/ritual com significados multifacetados enraizados na vida comunitária" (DÖRING, 2013, p. 168). Portanto, é impossível pensar o samba longe da dança e musicalidade enquanto meios políticos. Apenas destaco o quanto o cenário tem feito emergir o deslocamento do papel em outros espaços que o samba de roda hoje ocupa com outras maneiras de realizar o samba de roda que a patrimonialização reflete.

Importante ressaltar que o impacto da patrimonialização também causa tensão através das novas maneiras de organização que se instaura, 
sobretudo porque as políticas da patrimonialização não chegam de forma homogênea em todos os lugares por conta da delimitação do samba de roda do recôncavo, o que limita o alcance aos diversos grupos de samba existente na Bahia, e ao mesmo tempo, acaba por, segundo Oliveira (2015) com o fortalecimento e a capacidade de articulação política de alguns grupos que estabelece espaços e privilégios. O autor destaca que a burocratização da ASSEBA é um dos grandes pontos de tensão, uma vez que, pequenos grupos e de cidades mais distantes da sede da Casa do Samba, acabam por não conseguir se articular e ter acesso aos projetos.

Ao trazer essa reflexão, destaco que o samba de roda Voa Voa Maria pouco teve contato com as políticas da ASSEBA e quando teve foi sempre com tensão, o que desestimulou no grupo a buscar estar nos espaços realizados pela entidade, apesar de ser filiado a entidade. Além disso, a representação da ASSEBA na Ilha sempre foi instável, ou seja, em alguns momentos teve um diálogo presente, em outros não, e quando teve se apresentou ineficiente perante as propostas de mobilização que os representantes da ASSEBA apresentavam. Dessa forma, não houve nenhuma articulação forte com os grupos da Ilha de Itaparica e muito menos com a comunidade de Matarandiba que tem andado com suas próprias pernas e representações políticas e culturais há muito tempo e tem conseguido articular o samba de roda da comunidade em diversos espaços.

O Voa Voa Maria sempre questionou esses espaços por não enxergar neles um interesse pelos sambas da ilha, perante vários fatos e omissões: poucas reuniões realizadas na ilha e diálogos regulares com os grupos da ilha; pouca inserção dos grupos em eventos culturais; pouca mobilização constante com os grupos.

No entanto, o samba de Matarandiba, como a comunidade passa por uma forte mobilização através da Rede Matarandiba de Economia Solidária e Cultura, consegue ter acesso e contato com as pautas do samba e da patrimonialização, diferentemente dos outros grupos da ilha que pouco se inserem neste debate e tem bastante dificuldade para se manter.

Posto isso, observo que o samba de Roda Voa Voa Maria, com a sua reinvenção tem colocado novas possibilidades no fazer samba de roda na Ilha de Itaparica que perpassa por uma nova maneira de ocupar e se institucionalizar, ao mesmo tempo que, fortalece a sua prática e sua comunidade. 


\section{Da tradição ao ponto de cultura voa voa Maria: gravação do cd e economia solidária da cultura}

Dentro da dinâmica que passou a existir no samba de roda Voa Voa Maria, a sua organização tem buscado editais públicos e privados para financiar as suas atividades, um desses editais foi o dos Pontos de Cultura que a Secretaria de Cultura em parceria com o Ministério da Cultura lançou em 2014. Os Pontos de Cultura estão inseridos no Programa Cultura Viva, criado em 2004, com o objetivo de promover a produção, a pesquisa, o registro e a difusão das expressões culturais dos grupos e entidades responsáveis pelos modos de ser, pensar e fazer cultural no país, o Programa Cultura Viva tem como base a parceria da União, Estados, Distrito Federal e Municípios com a sociedade civil, no campo da cultura ${ }^{12}$.

Segundo Pereira (2008), o programa funciona como uma transferência de recursos do fundo público da cultura, por meio de concursos via edital (com regras públicas), que tem como destinatário um processo cultural já existente, em geral realizado por setores da sociedade civil. O programa entende o Estado não como realizador da cultura, mas como fomentador das diversas manifestações culturais do país, propondo uma política de cultura que abarque a dimensão simbólica "o MINC passou, portanto, a reunir três dimensões da cultura, buscando articular a dimensão simbólica da vida social, a dimensão da cultura como economia e a compreensão de cultura como direito de cidadania" (VILUTIS, 2011, p.1). Ademais, o programa tem uma dimensão da cultura e cidadania compreendida para a superação da exclusão social, eliminação das desigualdades e discriminações, a partir do reforço da autoestima e da apropriação do sentimento de pertencimento junto a comunidades (VILUTIS, 2011).

O programa se tornou política pública de Estado em 2014 através do projeto de Lei 757/2011, A Lei Cultura Viva foi sancionada pela Presidenta Dilma Rousseff em 22 de julho de 2014 e recebe o número 13.018/2014. A aprovação da Lei traz mudanças significativas no programa, sobretudo no que

\footnotetext{
12 Programa Cultura Viva - Documento Base (2013).
} 
diz respeito a definição dos beneficiários da política, pois constrói uma definição mais abrangente do que era. Com a mudança abrupta de governo, criou-se um quadro de profundas incertezas quanto à continuidade e avanço desta política do ponto de vista governamental (SANTINI, 2016).

Foi a partir de uma chamada pública lançada em 2014 que o Voa Voa Maria se tornou ponto de cultura premiado com a proposta de gravar um CD e um DVD, mas o recurso só foi liberado em 2017, quando as atividades começaram a ser realizadas. O projeto é dividido em três etapas: 1) oficinas de elementos percussivos, elementos vocais, elementos corporais e identitários; 2) gravação do CD e DVD e 3) circulação com três shows.

Para a realização das oficinas foi montada uma equipe de profissionais através de uma seleção pública com um coordenador musical, um oficineiro de elementos percussivos, uma oficineira de elementos vocais, uma oficineira de elementos coreográficos e uma oficineira de elementos identitários. Todo o processo de organização das oficinas foi realizado com o samba em reuniões para decidir dias, horários e formatos buscando sempre o diálogo e a horizontalidade. A intenção era de contar com pessoas que tivessem uma vivência com comunidades tradicionais e samba de roda, e entendesse que o papel era de troca e não imposição de um modelo ou descaracterizar o samba local, mas fortalecer a sua prática. A concepção de gravação do $C D$ não visava a questão financeira em primeiro lugar e sim um trabalho artístico e educativo.

As oficinas tinham como objetivo construir uma concepção artística tanto para as músicas com arranjos novos, melhorar o coro e vozes, quanto para a presença das sambadeiras como maneira de fortalecer a relação com o corpo e voz e com a identidade do samba de roda, sem perder a característica da estética do samba corrido ou de praia como as sambadeiras e sambadores identificam o Voa Voa Maria, típicos da região litorânea que:

\footnotetext{
integrem uma expressão de matriz africana fortemente ligada aos terreiros de candomblé. Este é um caso que sugere bastante a prática do samba de roda como uma continuidade do antigo batuque realizado através atabaques que executam ritmos ligeiros e repicados e de mulheres que sambam com movimentos acelerados, requebrados, sensuais, muitas vezes, emprestados das coreografias e gestualidades das danças dos orixás (DÖRING, 2013, p. 152).
} 
Esse fazer é ancestral que pode ter diversos contornos tanto de corpo, voz e toque conforme o momento e, portanto, não se enquadra em uma fórmula fixa. Além de ser uma formação em produção para que as sambadeiras e tocadores possam ainda mais se apropriar dessa prática, dos processos organizativos que englobam a produção do samba de roda.

A primeira etapa ocorreu de fevereiro a novembro de 2018 com oficinas durante todos os finais de semana (sábado e domingo). As oficinas tiveram um papel de fomentar um maior reconhecimento interno das sambadeiras e tocadores, de descortinar possibilidades do fazer samba de roda, que poderia ficar restrito em algumas pessoas por conta da posição nos espaços de decisão, por timidez ou mesmo por não achar que seria um espaço possível de novas perspectivas. Dentro desse cenário, destaco a participação das mulheres que passaram a compor mais músicas. Antes somente a Mestra Marica escrevia músicas para o samba, ao final das oficinas tinham sete músicas novas de quatro outras mulheres do samba (D. Aurea com quatro músicas, enquanto D. Margarida, D. Zélia e D. Vanda tiveram uma música) $)^{13}$.

Outro ponto de destaque foi o interesse tanto em cantar quanto em tocar das mulheres. O samba de roda Voa Voa Maria sempre teve duas solistas que eram Mestra Marica e Dona Zélia, novas sambadeiras passaram a cantar (D. Vanda e D. Aurea) e passaram também a se interessar pelos instrumentos ${ }^{14}$, função que somente os homens desempenham no samba. Mas, sobretudo, se destaca a participação das mulheres nos momentos de decisão, descentralizando falas e posturas que ficavam mais concentradas em quem desempenhavam funções de gestão na ASCOMAT ou nos homens, ao contrário, durante as oficinas foi possível ver mais mulheres falando, tomando decisões e alguns momentos se colocando contrária a posições muito incisivas dos homens.

A segunda etapa foi entrar em estúdio para gravação. O samba de roda foi para a cidade de Santo Antônio e passou três dias em estúdio

\footnotetext{
13 Para a gravação do CD foram escolhidas apenas dez músicas das novas composições.Não foram selecionadas uma música de D. Zélia e duas de D. Aurea.

14 O único instrumento tocado por mulher é o prato. Tocado somente por dona Gela, uma das mais antigas do grupo e que, pela idade está bem debilitada e já não consegue acompanhar o grupo. Com isso, hoje, o samba não tem o prato. D. Vanda, filha de Dona Gela, tem se mostrado interessada em dar continuidade.
} 
gravando, ${ }^{15}$ em uma experiência única para aquelas pessoas que nunca estiveram em um estúdio, nunca usaram determinados equipamentos ou tiveram a rotina e o modo de estar em gravação que é completamente diferente do que é fazer samba de roda na comunidade ou nas apresentações. Da mesma forma, buscaram aliar uma técnica de gravar que se faz com repetições, pausas, com uma direção musical preocupada com o modo de fazer samba de roda dessas pessoas, respeitando suas vozes, corpos e jeitos de tocar e sambar. De maneira que não destoasse do que eles realmente fazem, mas também pudesse aliar com a técnica de um estúdio para que o som tivesse a qualidade que um CD pode oferecer. As sambadeiras ficaram em uma sala, a percussão em outra e as cordas em outra e tudo era monitorado pelo produtor musical, e ao invés de gravar por partes - como usualmente se faz - o samba tocava junto pois é desta maneira que o grupo está acostumado a fazer. Depois desses três dias de gravação, a feitura do CD passou pela mixagem, masterização e parte gráfica. A parte gráfica também se realizou da mesma maneira, reuniões foram feitas com o grupo para escolha do que terá na arte do $\mathrm{CD}$ - capa e encarte -, os elementos escolhidos foram os que traduzem a realidade da comunidade como o mar, mangue, mariscos, sambadeiras e tocadores, com cores como amarelo, azul e verde. A última fase será a realização dos shows: um em Matarandiba, outro em uma outra comunidade da Ilha de Itaparica e um em Salvador.

A gravação do CD e DVD do samba de roda Voa Voa Maria concretiza um ciclo que o grupo iniciou desde que optou em reinventar a sua prática em diálogo com a reorganização comunitária com base na economia solidária, nas suas práticas culturais e nos reflexos da patrimonialização. Por estar inserido na Rede Matarandiba de Economia Solidária e Cultura a produção do CD não é vista apenas como um produto a ser comercializado, mas como a possibilidade de geração de renda para marisqueiras e pescadores que também são sambadeiras e tocadores, portanto, artistas da cultura popular, e que não se encaixam na ideia de consumo e mercado que muitas vezes é imposto a esses grupos

O processo criativo não pode ser instrumentalizado nem reduzido a mercadorias para o consumo, embora não se negue a importância de seus impactos econômicos. É

${ }^{15}$ Estúdio Universo Verde 
igualmente necessário considerar que essa produção cultural também movimenta um conjunto de sujeitos e redes sociais que são calcadas em identidades territoriais e muitas vezes se organizam em sistemas produtivos com lógicas próprias de funcionamento, alimentadas por relações solidárias e cooperativas, que nem sempre são mensuráveis em estudos e pesquisas econômicas nacionais (VILLUTIS, 2011, p. 4).

Abarca uma realização de um formato de produção que pensa o comércio de um bem dentro do conjunto das relações sociais e culturais locais, favorece a dinamização do território criando bens e serviços produzidos localmente e os próprios sambadeiras e tocadores sendo os responsáveis pela sua criação, produção e distribuição.

Ainda, tem construído uma ideia de valor dessas pessoas enquanto artistas da cultura popular, que tocam, cantam e dançam, organizam e produzem suas apresentações, indumentárias, músicas, tem feito um percurso que Döring (2013) sinaliza como ainda pouco refletido dentro da cultura popular "uma reflexão sobre seu fazer musical e artístico, sua concepção e performance estética (instrumentos, timbres, repertórios, improvisação, arranjos coreográfico e musicais, utilização de espaços, indumentárias, vestimenta)" (DÖRING, 2013, p. 171). Essas pessoas tem conseguido refletir sobre o seu fazer, o que abarca uma outra concepção do que eles produzem, bem como, outras maneiras de encarar esse fazer. "Hoje tem a preocupação de cantar certo, uma apresentação de um samba precisa ser organizada, ter compromisso, porque não estamos ali só pra gente."16

Esta reflexão também possibilita o reconhecimento dessa prática não somente por parte de quem faz, mas por um público que passa a se interessar pela cultura popular, dando maior visibilidade ao samba de roda sem que seja apenas um mero consumo de maneira efêmera e passageira, mas que contribui para que ele possa continuar realizando, uma vez que, os artistas da cultura popular passam a ser reconhecidos através de um caminho de troca:

se reconhece a via dupla das expressões estéticas das culturas populares, no sentido da visibilidade e do consumo cultural, que pode, sim, interessar tanto aos artistas populares quanto aos possíveis consumidores ou

${ }^{16}$ Mestra Marica - Entrevista em 14 de abril 2018, Matarandiba. 
participantes presentes em eventos tradicionais ou recriados (re-inventados) (DÖRING, 2013, p. 171).

Esses novos arranjos que a prática do samba de roda tem feito, podem contribuir para o seu fortalecimento através de um diálogo pautado pelo reconhecimento de quem faz e como faz, não estagnado em uma ideia muito cristalizada desses povos e comunidades, mas sim, da sua capacidade reinventiva. E que conseguem se apropriar de modelos e maneiras que pareciam distantes e quando apareciam se davam de maneira pouco horizontal, para uma forma onde os artistas da cultura popular trazem outras perspectivas em que se reconhecem como artista, e tem no reconhecimento, tanto interno quanto externo, um impulso para fortalecer algo que já realizam: "É muito gratificante ser reconhecido pelo o que a gente faz, a maioria aplaudindo é muito gratificante". ${ }^{17}$

Nesse sentido, o samba de roda Voa Voa Maria, tem desempenhado um papel importante no fazer samba de roda, pois provoca um deslocamento de que o samba de roda é algo estático e apenas consumo a partir da lógica da folclorização, ao contrário, tem conseguido através da gravação do CD e DVD fortalecer os laços comunitários, a sua organização e produção, se inserir em debates atuais na música criando espaços internos democráticos, além de reconhecer o papel artístico desse fazer. Novamente tomo Döring (2013), que destaca a importância dessas novas roupagens para contribuir com o reconhecimento e a continuidade das culturas populares

não somente no sentido de devoração por parte de uma classe média, mas também para que as pessoas que se aproximam, se deixam "devorar" pelas musicalidades, poesia, pelos movimentos, gestos e principalmente pelas personalidades interessantes e eloquentes que podem se conhecer no universo do samba de roda, como nas demais tradições de matriz africana (DÖRING, 2013, p. 171).

Refletir acerca da reinvenção do fazer samba de roda do Voa Voa Maria é estar na perspectiva das mudanças pelas quais passa a cultura popular e do quanto essa prática é reveladora de um potencial em que povos e comunidades têm se apropriado, em diálogo com o seu fazer, que compõem novas estratégias para fortalecer o samba de roda enquanto uma tradição

${ }^{17}$ Mestra Marica - Entrevista em 14 de abril 2018, Matarandiba. 
diaspórica e de resistência. Ao mesmo tempo que se apropria de espaços onde sambadeiras e sambadores são os seus próprios produtores e se reconhecem enquanto artistas da cultura popular. Além de ser um fazer que se reflete justamente na sua possibilidade inventiva e que tem fortalecido povos e comunidades.

\section{Conclusão}

As transformações pelas quais passam a cultura popular apontam para mudanças na sua concepção que tem buscado um novo lugar que abandone ideias essencialistas ou folclóricas, tornando-se cada vez mais dinâmica e com mobilizações que pautam o fortalecimento de suas raízes e identidades. O samba de roda, inserido nesse cenário, e desde a sua patrimonialização, reflete este novo lugar e vem ganhando outros contornos no seu fazer e nos diversos campos que o compõem tanto esteticamente, como artístico e politicamente.

Desta forma, comunidade e grupos têm se mobilizado em volta de uma organização que possa dar conta dessas novas possibilidades sem perder as suas referências e memórias, mas dialogar com o momento posto. É nesse contexto que o samba de roda Voa Voa Maria passa a se re-organizar em volta das práticas econômicas solidárias e das políticas de patrimônio como maneira de fortalecer a sua prática tanto dentro da comunidade de Matarandiba como fora.

Através da organização comunitária, acesso a políticas de cultura e patrimônio e em diálogo com as entidades que pautam essa política na região, mesmo que ainda de maneira escassa e desorganizado, o samba de roda consegue se pautar e inserir nessa política, fortalecendo seus espaços com maior articulação na comunidade e entre os integrantes do grupo, destacando a participação das mulheres.

O ápice desse processo é a gravação do primeiro CD e DVD do samba de roda que tem possibilitado uma experiência que coloca o samba Voa Voa Maria dentro de formatos onde os seus integrantes se tornam produtores e artistas da cultura popular, debatem o seu fazer de maneira artística e reconhecem o seu valor dentro da produção cultural. Não apenas como algo exótico, mas deslocando esse olhar para o reconhecimento de uma prática 
que é muito mais profunda e que precisa ser vivenciada de várias maneiras, inclusive como artistas e produtores culturais.

Portanto, a prática do samba de roda Voa Voa Maria tem se deslocado e se colocado como um fazer que se dá no diálogo com as políticas de patrimônio, da produção cultural e da economia solidária e possibilita a sua organização de maneira mais horizontal, aberta e dinâmica. Ao mesmo tempo em que preserva a sua memória para fortalecer a sua identidade e a sua constante transformação, não sendo estático, mas sim, um fazer do cotidiano, de pés e mãos que tocam, de vozes que cantam o seu lugar e de corpos abertos que carregam memórias e criam novos caminhos.

\section{Referências}

ABIB, Pedro Rodolpho Jungers. Capoeira Angola: Cultura Popular e o jogo dos saberes na roda. 2. ed. Salvador: EDUFBA, 2017.

ARANTES, Antônio A. Patrimônio Imaterial e Referências Culturais. Revista TB, Rio de Janeiro, 147. 129/139, out-dez. 2001.

DÖRING, Katharina. Umbigada, encanto e samba no pé: O feminino na roda. Interfaces Científicas - Humanas e Sociais, Aracaju, V4. Ed Especial, p 9-22. nov 2015.

DÖRING, Katharina. Samba de Roda: Visibilidade, consumo cultural e estética musical. Pontos de Interrogação, v.3, n.2, jul./dez., 2013.

FRANÇA FILHO, Genauto Carvalho de; LAVILLE, Jean Louis. Economia Solidária: Uma abordagem internacional. Porto Alegre: Editora da UFRGS, 2004.

MANESCHY; SIQUEIRA; ÁLVARES: Pescadoras: subordinação de escadoras: subordinação de gênero e empoderamento. In: Estudos Feministas, Florianópolis, 20(3): 384, setembro-dezembro/2012.

GRAEFF, Nina. Os ritmos da roda: tradição e transformação no samba de roda. Salvador: EDUFBA, 2015.

OLIVEIRA, Marcus Bernardes Silveira: A tradição em dois escopos: patrimônio cultural e sambas de roda. In. Antítese. v. 8, n. 16, p. 279-302, jul./dez. 2015.

PEREIRA, João. Programa Cultura Viva: Políticas Culturais para a emancipação das classes populares. Dissertação de Mestrado. 2008. Programa de Pós-Graduação em Políticas Públicas e Formação Humana da Universidade do Estado do Rio de Janeiro. 
PROGRAMA CULTURA VIVA - Documento Base, São Paulo, julho de 2013.

ECOSMAR. Relatório do mapeamento de produção e consumo local. Salvador: ITES, vs. 2008. Não Publicado.

SHALINS, Marshal. O "pessimismo sentimental" sentimental e a experiência etnográfica: por que a cultura não é um objeto em vias de extinção (parte I). MANA 3(1): 41-73, 1997.

SANTINI, Alexandre. Cultura Viva Comunitária: A possível construção de um repertório comum para as Políticas Culturais na América Latina. Dissertação de Mestrado. 2016.

SAMBA de Roda do Recôncavo baiano. Brasília: IPHAN, 2006. (Dossiê IPHAN, 4).

UNESCO. Convenção para a salvaguarda do patrimônio cultural imaterial. Paris, Jul. de 2003.

VILUTIS, Luana. Pontos de cultura e economia solidária - aproximações e possibilidades. In: II Seminário Internacional de Políticas Culturais. Rio de Janeiro: Fundação Casa de Rui Barbosa, 2011.

Recebido em: 31/10/2018

Aprovado em: 04/12/2018 